\title{
A respeito da vida antropológica e da novelização do conhecimento: Reflexões a partir do livro Euphoria, de Lily King
}

About anthropologic life and the novelization of knowledge: Reflections about Euphoria, from Lily King

Igor José de Renó Machado

\section{(2) OpenEdition Journals}

\section{Edição electrónica}

URL: http://journals.openedition.org/aa/3048

DOI: $10.4000 /$ aa.3048

ISSN: 2357-738X

\section{Editora}

Programa de Pós-Graduação em Antropologia Social (UnB)

\section{Edição impressa}

Data de publição: 1 julho 2018

Paginação: 329-346

ISSN: 0102-4302

\section{Refêrencia eletrónica}

Igor José de Renó Machado, «A respeito da vida antropológica e da novelização do conhecimento: Reflexões a partir do livro Euphoria, de Lily King», Anuário Antropológico [Online], v.43 n. 1 | 2018, posto online no dia 26 maio 2019, consultado o 28 abril 2021. URL: http://journals.openedition.org/aa/3048 ; DOI: https://doi.org/10.4000/aa.3048

\section{(9) $\odot \Theta \Theta$}

Anuário Antropológico is licensed under a Creative Commons Atribuição-Uso Não-Comercial-Proibição de realização de Obras Derivadas 4.0 International. 


\section{A respeito da vida antropológica e da novelização do conhecimento: reflexões a partir do livro Euphoria, de Lily King}

Igor José de Renó Machado

UFSCar

Fazer uma discussão com propósito acadêmico de um livro de literatura não é uma tarefa simples, mesmo que o livro trate de uma história crucial no desenvolvimento da antropologia do século XX. O livro de Lily King (2014), Euphoria, refere-se ao curto espaço de tempo entre 1931 e 1932, quando Margaret Mead, seu então marido Reo Fortune e seu futuro marido Gregory Bateson se encontraram durante o trabalho de campo na Nova Guiné, às margens do rio Sepik. A obra discute tanto as tramas complicadas das relações entre os três como o desenvolvimento de ideias e reflexões especialmente importantes para a história da antropologia. O romance procura transformar as experiências de trabalho de campo num personagem central de um mundo de ficção.

O livro é uma ficção baseada nos fatos reais desse encontro etnográfico, mas sem qualquer compromisso com a "realidade". Isso fica muito evidente ao final do livro, quando o destino dos personagens principais é completamente diferente daquele que aconteceu na vida real. Mas, ao mesmo tempo, toda a construção da narrativa de King é absolutamente factível com o conjunto de documentos que registram esse momento tão especial na história da antropologia. As informações vêm do volume assustador de cartas escritas por Margaret Mead, das biografias sobre Mead e Bateson, dos autorrelatos biográficos de Mead, das entrevistas variadas de Bateson e Mead e, bem, de quase nada sobre Fortune (voltaremos a isso mais adiante).

Assim, o desafio que me coloco nesse texto é pensar como a leitura desse romance - ganhador do kirkus Prize de 2014, do New England Book Award for Fiction de 2014 e finalista do National Book Critics Circle Award de 2014 - pode nos levar a pensar sobre antropologia, etnografia e história da antropologia. Ou seja, busco uma reflexão sobre o que esse romance pode dizer aos antropólogos de forma geral, sem buscar uma análise de caráter literário. ${ }^{2}$

Lily King teve a ideia de escrever o romance após se deparar com uma das 
biografias de Margaret Mead, ficando interessada especificamente naqueles 5 meses de encontro entre os três antropólogos no rio Sepik. ${ }^{3} \mathrm{O}$ livro começou a ser escrito como um "romance histórico", mas logo, nos diz King, os personagens começaram a ganhar vida e a romancista assumiu a escrita, elaborando outras possibilidades a partir do material histórico. De certa forma, o livro tem como origem o fascínio de King por Mead. ${ }^{4}$

A trama do livro é simples: Mead e Fortune (que no livro ganham o nome de Nell e Fenwick) encontram-se com Bateson (Bankson) num Natal celebrado no posto governamental da Nova Guiné. O casal está em busca de uma tribo para fazer o terceiro trabalho de campo seguido com uma população diferente (haviam estado entre os Arapesh e os Mundugumor, que também ganham nomes diferentes no romance). Bateson/Bankson os ajudará a encontrar essa terceira população, os Tchambuli, depois conhecidos antropologicamente como Chambri. Esse encontro dispara um triângulo amoroso complexo, que produzirá na "vida real" a ruptura com Fortune e o casamento de Mead e Bateson. Dispara também a produção de trabalhos etnográficos clássicos, como Sexo e Temperamento (2000 [1935]), de Mead, e o Naven (2006 [1936]), de Bateson, bem como tem influência em outros trabalhos igualmente clássicos, como o Sorcerers of Dobu (1963 [1932]), de Fortune e Padrões de Cultura (2003 [1934]) de Ruth Benedict.

O triângulo amoroso é mais um quadrado, na verdade, uma vez que o relacionamento amoroso entre Mead e Ruth Benedict também perpassa o livro de King, bem como a experiência de campo de Mead, Fortune e Bateson. O clímax do livro, por exemplo, se dá em torno da leitura do manuscrito de Padrões de Cultura, que dispara uma intensa produção de ideias nos três antropólogos perdidos num campo muito distante: ideias que resultarão na conexão de uma perspectiva teórica com uma perspectiva das relações pessoais entre os personagens.

Esse roteiro, simplificado, pode ser descrito como o roteiro da "vida real", pois, de fato, tudo isso aconteceu. O que o livro faz é transformar essa narrativa num romance, construído a partir do ponto de vista de Bankson (Bateson), entremeado com trechos do diário de Nell (Mead). Isso é possível dado o número incrivelmente grande de informações sobre este único evento, graças, principalmente, às cartas de Mead ${ }^{5}$ e sua autobiografia (Mead, 1972) e às biografias sobre a vida de Mead (Howard, 1984; Bateson, M., 1984). 


\section{Historiografia romanceada da antologia}

O livro apresenta uma potencialidade que não deve ser desprezada por antropólogas/os, principalmente aquelas/es interessadas/os em ensinar a história da antropologia na primeira metade do século XX, no período dos discípulos de Boas, por assim dizer. Ao relatar de forma ficcional um complicado quadrilátero amoroso, do qual resultaram grandes obras da antropologia, é inevitável que se passe por uma vontade de conhecimento sobre os fatos nas suas várias narrativas. Assim, depois de acabar o livro, me apressei em comprar uma das biografias de Mead e encontrei diversos artigos sobre esse período de campo na Nova Guiné, textos sobre Bateson e até mesmo sobre Reo Fortune. E, por fim, me vi lendo novamente Sexo e Temperamento e o Naven. Se fosse só por isso, a leitura do livro valeria muito a pena, pois é um grande estimulador de vontade de saber: ficamos nos perguntando, "mas será que isso foi assim mesmo?", "será que há algo como isso?", "acho que aqui temos uma invenção" etc.

Imaginando esse uso em sala de aula, pode-se ter certeza que o conhecimento novelizado que Lily King nos apresenta é um grande estímulo a um mergulho cuidadoso na história da antropologia. É muito fácil imaginar alunos que tenham o interesse despertado para esse momento da história da antropologia ao entrar em contato com o livro de Lily, que é extremamente fácil de ser lido, afinal é um romance que prende quem o lê desde as primeiras páginas.

O livro joga luz sobre uma conexão poderosa entre os quatro livros clássicos produzidos pelos personagens reais. O livro de Reo Fortune deriva de um trabalho de campo anterior, entre 1927 e 1928, com os nativos da ilha de Dobu, na Nova Guiné (uma ilha muito próxima a Trobriand, a ponto dos dobuanos terem feito parte do Kula, descrito por Malinowski (1978 [1922])). Foi ao voltar dessa viagem que Fortune conhece Mead em um navio, ele seguindo para Inglaterra e ela voltando aos EUA. Sorcerers of Dobu foi efetivamente escrito ao longo de 1930 e 1931 (publicado em 1932), junto à Mead, enquanto Reo preparava seu doutoramento na Universidade de Columbia e os dois dividiam um apartamento em NovaYork. Assim, o livro é fruto de um diálogo constante com Mead, bem como com Ruth Benedict, com quem Mead dividia um amor constante e expresso em milhares de cartas (Lapsley, 2001). A etnografia de Fortune sobre os Dobu é um dos casos analisados no livro de Ruth Benedict, Padrões de Cultura. A reflexão de Benedict sobre os padrões de cultura passa pela relação entre Mead e Fortune e por esses anos antes do campo conjunto dos dois na Nova Guiné. 
Por outro lado, o manuscrito de Padrões de Cultura foi enviado por Benedict à Mead enquanto eles estavam no campo (no caso, enquanto ainda estavam entre os Arapesh). A leitura conjunta desse livro por Mead e Bateson, acompanhados desconfiadamente por Fortune, teve grande impacto na experiência de campo e na futura escrita dos clássicos Sexo e temperamento e Naven.

Derivação da perspectiva boasiana, a ideia dos padrões de cultura de Benedict - e a distinção entre culturas apolíneas e dionisíacas - inspira diretamente a forma como Mead interpretaria o próprio campo e as comparações que estabelece entre os Arapesh, Mundugumor e Tchambuli. As noções de eidos e ethos, fundamentais ao livro de Bateson, são uma influência explícita da antropologia de Benedict e Mead, com sua inclinação psicologizante.

Assim, o encontro entre Mead, Fortune e Bateson pode nos levar a pensar grandes desenvolvimentos da antropologia do século XX, desde o desenvolvimento do boasianismo peculiar de Benedict e Mead até a crítica ao funcional-estruturalismo por Bateson. O livro de King joga-nos diretamente nesse contexto, como uma novelização ${ }^{6}$ da história da antropologia na relação entre esses personagens tão complexos.

\section{A teoria dos quadrados e a conexão entre vida e antropologia}

O clímax do romance é o desenvolvimento da "teoria dos quadrados", ${ }^{7}$ ou no livro, o "grid". Essa parte é realmente interessante e leva o romance a um patamar mais sofisticado de entendimento da teoria antropológica, se espraiando para refletir sobre a relação entre a produção da teoria e a vida particular de cada antropólogo, com suas vicissitudes, relações, amores, aversões etc. A teoria dos quadrados, ou o grid na versão de Lily King, foi um esboço de teoria geral do desenvolvimento, tanto das culturas como das personalidades, construída no diálogo de Mead e Bateson a partir da leitura do manuscrito de Ruth Benedict. Em suas cartas, Mead conta a grande excitação de desenvolver a teoria dos quadrados e como isso, de certa forma, vai marcar toda a experiência intelectual da autora posteriormente.

Nas cartas, por exemplo, é comum que ela se refira a pessoas por posições que imaginam ter no "quadrado". Culturas são colocadas em lugares específicos no "quadrado". Relações culturais e também pessoais são imaginadas a partir dessas posições atribuídas no quadrado. Ou seja, no que concerne a algumas pessoas a relação poderia ser mais fácil se eles compartilhassem do mesmo lugar 
nos quadrados, por exemplo. Não é por menos que, ao desenhar esse esboço, uma das primeiras reações de Mead e Bateson foi colocarem-se na mesma posição dentro do quadrado, enquanto Fortune foi colocado no lado diametralmente oposto desse esquema, indicando já um início do tipo de relação que se colocaria entre os três num futuro próximo (a separação de Mead com Fortune e o posterior casamento com Bateson).

Mas o que era exatamente o quadrado? Era um esquema simples de dois eixos perpendiculares, dividido em posições geográficas (norte, sul, leste e oeste), no qual são colocadas as culturas (e depois as pessoas) em relação a alguns índices de diferenciação. A teoria dos quadrados é declaradamente inspirada na distinção que Ruth Benedict faz entre sociedades apolíneas e dionisíacas e nos modelos de personalidade de Jung (2011). As populações do "norte" seriam agressivas, possessivas, competitivas e assertivas. As do "sul" seriam suaves, compreensivas, flexíveis, compassivas e dóceis. Esse é o contrate básico no eixo norte/sul. As sociedades do "oeste" seriam pragmáticas, organizadas, sistemáticas, marcadas por contrastes fortes. As sociedades do "leste" seriam criativas, espirituais, artísticas, sem contrastes fortes. Entre esses quatro pontos cardinais estariam todas as populações humanas, ou ao menos grupos dentro de sociedades, que poderiam escolher dividir seus coletivos internos por esses pontos geográficos, como a sociedade americana, que daria características de "norte" para os homens e de "sul" para mulheres.

Vê-se nesse "quadrado" os fundamentos do futuro livro de Mead, Sexo e Temperamento. Mead usaria o quadro para diferenciar os Arapesh (populações do Sul) dos Mundugumor (Norte) e dos Tchambuli (onde mulheres seriam "norte" e homens "sul"). Embora escrita durante a estadia de Mead e Fortune entre os Tchambuli, enquanto Bateson estava em uma aldeia Iatmul do outro lado do lago Chambri e fazia visitas frequentes, a teoria dos quadrados nunca foi efetivamente publicada. Mas o texto original está conservado na Biblioteca do Congresso nos EUA. ${ }^{8}$ O texto nunca foi publicado, provavelmente, pelo pendor um tanto "fisiológico" do argumento, pensando em determinados comportamentos como naturais, no limite.

Esse caráter fisiológico está implícito (e também explícito) no argumento de Sexo e Temperamento, onde a questão da relação entre temperamentos, vistos como naturais, e o que chamaríamos hoje de papéis de gênero se coloca em termos bastante problemáticos. Tendo chegado à conclusão (na linha de Ruth 
Benedict e Boas) de que as culturas escolhem determinados tipos de comportamento como preferenciais, e depois escolhem se esses comportamentos serão igualmente divididos entre homens e mulheres, ou se esses grupos (e outros possíveis, como grupos etários, castas, etc.) teriam cada um seu próprio código de comportamentos preferencial, Mead deve lidar com a questão do desviante.

"Suponhamos que existam diferenças temperamentais definidas entre seres humanos que, se não são inteiramente hereditárias, pelo menos são estabelecidas numa base hereditária logo após o nascimento. (...) Estas diferenças, finalmente incorporadas à estrutura de caráter dos adultos, constituem, então, as chaves a partir das quais cada cultura atua, selecionando como desejável um temperamento (...). (Mead 2000:271, grifo meu)

A questão do desviante leva a algo como uma "base hereditária", que produziria temperamentos humanos variados, muitos deles difíceis de se adaptar a determinadas escolhas feitas para os comportamentos padrões de uma cultura (mas não ao de outras, estando aí a aleatoriedade). Esse detalhe da perspectiva de Mead, já esboçada na teoria dos quadrados, esconde um potencial possivelmente racializante que não escapou a Lily King. No romance, a teoria dos quadrados é assinada por Mead e Bateson (Fortune não quer participar disso). Essa teoria, no romance, depois teria sido apropriada pelo nazismo justamente por esse traço racialista: nazistas seriam a raça primordial do "norte" e, como tal, deveriam agir sobre as outras. Isso levou Bateson (no romance, lembremos, Bankson) a retirar de circulação todas as impressões da teoria, renegando suas próprias ideias em função da apropriação nazista.

$\mathrm{Na}$ "vida real", o texto seria assinado por Mead e Fortune, embora completamente escrito por Mead a partir das conversas com Bateson sobre a leitura do Padrões de Cultura de Ruth Benedict. Mead se sentia em débito com Fortune, afinal, a ideia surge a partir da experiência de campo conjunta que faziam até ali. Mas Fortune se recusa a assinar a teoria, rabisca seu nome do manuscrito e escreve acima: "não tenho nada a ver com isso". 


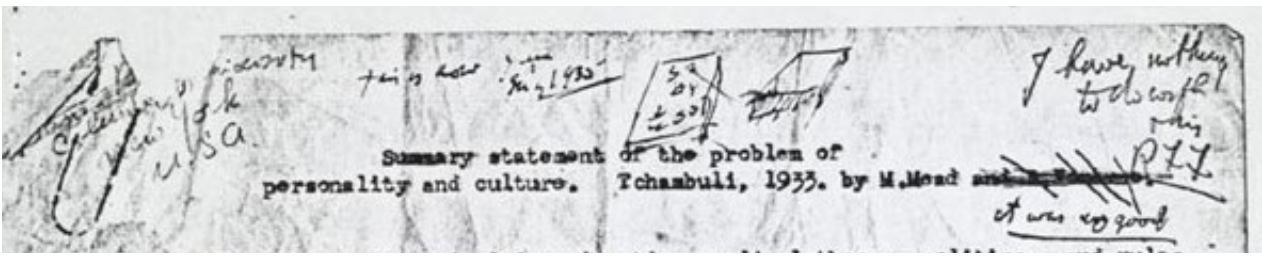

Acima podemos ver a parte inicial do texto, com a mensagem de Fortune (Mead, M. [e Reo Fortune] 1935), que passaria muito tempo, depois da separação, criticando essa ideia, justamente pelo potencial racialista que ela contém.

Dobrin e Bashkow (2010) compilaram nesse parágrafo as várias respostas de Fortune à teoria dos quadrados, a partir de cartas de Fortune para Mead, durante o processo de separação e muito tempo depois:

\begin{abstract}
"As Fortune saw it, Mead was committing herself to a "race campaign . . a as deliberate as Hitler's." She was dividing humanity into two (primary) races, one Southern and one Northern, each with its own "pharmacopeia," "literature," "appropriate cultures among the cultures of the world," and "appropriate sex affairs." These "world distributed races" were "believed to have a real physiological basis, like blood groups." Moreover, Fortune saw Mead as using this categorization "to make the stock race points": to "question the wisdom of intermarriage" between the races, to "give them their own separate cultures in mutually unintelligible languages," and to "start a campaign against other races than your own." If the theory of the squares did not grow out of "weak mindedness," it could only represent the "self-conscious" advancing of a "vicious campaign" of which he was the first victim.” (Dobrin e Bashkow, 2010:90)
\end{abstract}

Fortune criticava o antiboasianismo das teses da teoria dos quadrados, que embasou a reflexão do Sexo e Temperamento. Lily King, que fez uma profunda pesquisa para escrever o livro, provavelmente encontrou esses argumentos, ou nas cartas de Fortune a Mead, ou nos poucos textos sobre Fortune que a historiografia da antropologia produziu. Mas Fortune também se revoltou com a teoria dos quadrados por um motivo muito mais específico: Mead e Bateson o classificaram pessoalmente como um homem "norte", ao passo que eles seriam pessoas "sul". Isso significava, desde o começo, que haveria uma sintonia entre Mead e Bateson que não havia entre Mead e Fortune, indicando o começo da relação entre Mead e Bateson já ali, entre os Tchambuli, fato que não passou despercebido a Fortune: ele foi colocado como um exemplo do "norte". 
Num certo sentido, a epifania dos quadrados era também uma expressão da relação entre Bateson e Mead, que nascia ali e excluía Fortune. A rápida passagem entre culturas e pessoas que a teoria produziu ali no próprio momento de produção é retratada por King no romance, assim como atestada pelas cartas que Mead trocou com Fortune e Bateson. A teoria passou a ser, na verdade, uma forma ordinária de Mead considerar todos aqueles que conhecia, e assim se referia às pessoas como "norte", "sul”, "nordeste” etc. Qualquer um caía no "grid”. Essas nomenclaturas estão espalhadas pelas cartas que escreveu ao longo da vida.

Dobrin e Bashkow avançam a hipótese de conexão entre a relação pessoal e a forma de resolver relações amorosas tensas com a produção de reflexões teóricas mais amplas (Dobrin e Bashkow, 2010:81). Assim, podemos ler a teoria dos quadrados como uma dupla manifestação: um esquema para pensar as culturas e um esquema para lidar com pessoas diferentes e emoções conflitantes. Essa característica é densamente explorada por King, revelando uma sensibilidade sobre a forma como o pensamento social é constituído em processos que articulam a vida pessoal e a reflexão abstrata sobre o mundo. As teorias respondem, também, a questões muito particulares de seus proponentes. King produz, assim, uma novelização de um processo de interconexão entre vida e teoria que pode ser muito útil para produzir reflexões críticas sobre a escrita antropológica, mesmo lidando com um objetivo completamente ficcional.

Essa interconexão nos levaria a pensar sobre os limites da escrita etnográfica, por exemplo. Até que ponto há uma transposição, na análise antropológica, das dimensões do que poderíamos chamar de "idiossincrasias emocionais" das/ os antropólogas/os? As etnografias escondem projeções inconscientes, como parece ser o contraste construído por Mead entre os Arapesh (sul) e Mundugumor (norte) uma metáfora do contraste entre a própria Mead (sul) e Fortune (norte)? Por outro lado, seria possível entender a novelização que expõe essa dimensão menos evidente da produção do conhecimento antropológico como uma escrita antropológica em si? Um exercício de ficção, nesse caso, poderia ser um exercício efetivamente antropológico? Todas essas questões são difíceis de responder, obviamente, mas indicam o tipo de reflexão que o romance de King pode despertar.

Fortune, por sua vez, entendeu e reagiu à teoria dos quadrados e ao lugar no qual foi colocado pela reflexão de Mead e Bateson (segundo Dobrin e Bashkow, 2010:92). O conhecimento usual da história da antropologia é de que, após 
a separação com Mead, Fortune ficou tão frustrado que nunca mais produziu qualquer coisa significativa. O último livro publicado por Fortune, em 1942, foi uma gramática Arapesh. As cartas trocadas com Mead, que se estenderam até muito além da separação, indicam esse inconformismo com sua classificação pela teoria e, de certa forma, dão azo à interpretação de que tenha, de fato, ficado obcecado com isso, de forma a não seguir adiante com sua carreira, como o fizeram Mead e Bateson.

\begin{abstract}
"I have been thinking a [great] deal about myself as being Northern Race i.e. possessive, jealous, proud, sadistic, violent... I had to accept a factual situation [that is, Mead's attraction to Bateson], and also apparently eternal reason for it - to the permanent discredit of my own being and nature... I was given a bad name, with authority of Science... [It] makes a man bad." He went on to say, "I was persuaded for a while it was Science and I was a bad Race by heredity... But I'm not like that.... It has nothing to do with me." (Fortune apud Dobrin e Bashkow, 2010:92.) ${ }^{9}$
\end{abstract}

O que nos interessa aqui pensar é como um romance sobre o trabalho de campo a partir de "fatos reais" ${ }^{10}$ pode nos levar a refletir sobre as conexões entre a vida particular dos antropólogos, com suas idiossincrasias, desejos, complicações, idealismos, e a produção de teorias supostamente abstratas e generalizantes. Lily King coloca a vida antropológica num primeiro plano, de forma muito instigante, a ponto de produzir um desejo mais detalhado de conhecimento das vidas individuais e das teorias produzidas pelos personagens.

\title{
Controvérsias e narrativas dominantes
}

Outro conjunto de questões que a leitura do romance de King pode levantar é sobre o efeito que ele pode ter sobre outras narrativas que se desenvolveram ao longo do século XX. Refiro-me aqui a duas, especificamente: as narrativas da controvérsia Mead-Freeman, das décadas de 1980 e 1990, por um lado, e as narrativas sobre Reo Fortune, inspiradas longamente na forma como Mead passou a retratá-lo em suas inúmeras cartas. Uma narrativa tem como centro a credibilidade da própria Mead, a outra a credibilidade de Fortune. Veremos como essas duas narrativas são tocadas e influenciadas pelo romance de King (ou como o romance é influenciado por elas, para ser mais preciso.)

A controvérsia Mead-Freeman ${ }^{11}$ iniciou-se após a morte de Mead (1978), 
com a publicação do livro de Derek Freeman (1983), no qual o autor criticava abertamente o primeiro trabalho de Mead, aquele que a lançou ao "estrelato", tanto no seio da antropologia como entre o público em geral norte-americano, o Coming of Age in Samoa (1973 [1928]). O livro, como se sabe à exaustão, relativizou a ideia de adolescência em vigor no momento, lida principalmente como um processo biológico que levaria às tensões e rebeldia características desse momento na vida. Seria, portanto, um processo universal do qual não se poderia fugir. Mead encontrou, entretanto, uma adolescência tranquila e não "problemática" em Samoa, o que lhe permitiu questionar o modelo psicológico largamente aceito até ali: se as coisas eram diferentes em Samoa, a adolescência não poderia ser um processo biológico. Se não era biológico, certamente, seria preciso atribuir às culturas a criação dessas fases de desenvolvimento das crianças (e quaisquer outras).

Freeman atacava a descrição etnográfica de Mead: os samoanos não seriam tão pacíficos assim, havia uma longa história de agressão e violência entre eles, era comum a ocorrência de estupros, etc. Além disso, Mead teria sido enganada pelas "nativas" no que tange à vida sexual, pois o que as mulheres diziam sobre a facilidade da vida sexual mais livre era evidentemente apenas uma piada que a autora não conseguiu entender. As críticas de ganharam um grande apelo público, impulsionado por jornalistas e por um documentário realizado por Freeman. Esse processo levou a uma depreciação da figura pública de Mead, justamente a esfera na qual ela envolveu tanto esforço para se destacar e que a transformou num ícone norte-americano. O livro de Freeman e o barulho em torno dele afetaram a imagem pública de Mead, como afirma Shankman. ${ }^{12}$

No seio da antropologia, entretanto, essas críticas receberam muito menos crédito e, já em meados da década de 1990, a ideia de que Freeman exagerara enormemente e que seus julgamentos sobre a obra de Mead eram muito mais uma forma de autopromoção que de análise antropológica eram consenso. Segundo Coté, por exemplo,

“(...) few scholars aware of the issues concerning Samoan history, adolescence, or cultural anthropology endorsed Freeman’s polemic about Mead (...)”(Coté, 2000:533).

$\mathrm{Ou}$ 
“(...) there is a consensus that Freeman's case against Mead is flawed in several fundamental ways, including how he has characterized Mead's views on evolution and her place in the "Boasian paradigm," as well as his popular claim that Mead was hoaxed into believing she had found a "free-love society." In addition, we concur that Freeman has gone to great lengths to create a sensational story that is out of proportion with historical reality."(Coté, 2000:536)

Dado este contexto de depreciação da imagem pública de Mead, qual o impacto do romance de King nessa narrativa? Se no seio da comunidade antropológica o trabalho de Mead parece ter se mantido valorizado, o mesmo não se pode dizer do que aconteceu na "opinião pública”. Thomas H. Eriksen, em uma resenha do livro de King em seu site, ${ }^{13}$ nos diz que um dos méritos do romance é mostrar uma Mead trabalhadora, frágil, vulnerável e extremamente sagaz, de forma a reconstituir à figura pública de Mead algo da notoriedade perdida com a controvérsia. Euphoria executaria, nesse sentido, o papel de uma contranarrativa, mesmo que num nível ficcional. Esta contranarrativa resgataria Mead das críticas exageradas de Freeman, ao construí-la sensível e cuidadosamente em toda seriedade do seu comprometimento com a produção do conhecimento, que é evidente ao longo de todo o romance (e, claro, ao longo da obra de Margaret Mead).

Carole McGranahan, num texto para o website antropológico Savage Minds ${ }^{14}$, por sua vez, destaca que a atenção despertada por Mead como figura pública justifica o investimento nessa figura icônica norte-americana do século XX. Essa renovação do interesse público na figura de Mead é, para McGranahan, uma forma de ultrapassar as décadas de 1980 e 1990, que não foram gentis com ela. Alma Gottlieb, em outra resenha, ${ }^{15}$ lamenta profundamente o final do livro de King, no qual o destino do personagem de Mead (Nell) diverge completamente do que aconteceu na "vida real". Gottlieb não vê sentido em retirar de Mead/ Nell o que efetivamente se passou na vida de Mead, considerando que sem ela a história da antropologia no século XX teria sido completamente diferente e, certamente, muito menos interessante. De uma forma ou de outra o romance de King parece refazer uma narrativa menos desfavorável à Mead, restabelecendo algo do seu lugar de fascínio nos EUA.

O mesmo não poderíamos dizer da imagem e narrativa que o romance traz de Reo Fortune (Fenwick). E aqui tocamos na questão sobre o poder da narrativa dos vencedores. É preciso saber, primeiro, que Fortune foi o grande per- 
dedor nessa história: supostamente abalado pelo fim do casamento com Mead, nunca mais conseguiu se recuperar, a ponto de não produzir mais nada de significativo depois daquele momento crucial no rio Sepik. Esse é o conhecimento comum à história da antropologia, com o qual o romance de King comunga e, digamos, radicaliza. Conhecido como uma "pessoa difícil”, teimoso e intratável no folclore acadêmico, no livro de King todas essas características são levadas ao paroxismo da vilania: ao final do romance, temos em Fen um vilão típico. Ele é violento, egoísta, estimula um roubo de uma flauta sagrada pelo qual o nativo que o acompanha é assassinado, ato que leva ao final da possibilidade do trabalho de campo, do qual os três gringos devem fugir imediatamente. Essa história do romance é completamente ficcional. O fim do trabalho de campo "real" foi sem esse tipo de emoção e, durante um tempo, Mead e Fortune permaneceram casados, mesmo que distantes um do outro.

O romance, portanto, trabalha contra a imagem pública de Fortune: ele é um vilão. Essa vilania é completamente construída a partir das cartas de Margaret Mead para muitos de seus amigos, falando sobre Fortune e sua personalidade. Como afirmam Dobrin e Bashkow (2010:113) a imagem que Mead construiu de Fortune não era nem de longe "desinteressada". Houve um trabalho constante de Mead em desacreditar e afastar Fortune nos meios antropológicos. Mas é preciso ponderar que Mead também foi constantemente alguém que procurou ajudar Fortune a conseguir empregos nos 15 anos entre sua contratação em Cambridge e os anos do triângulo amoroso no rio Sepik. Segundo os autores, havia um temor que Fortune desqualificasse o trabalho de Mead, com base no trabalho de campo conjunto que fizeram. E aqui voltamos à teoria dos quadrados. Como Fortune desacreditava radicalmente dos quadrados de Mead (o que se vê em inúmeras cartas de Fortune à Mead), e como a análise de Sexo e Temperamento era essencialmente uma transposição disfarçada dos quadrados para a análise comparativa entre os Arapesh, Mundugumor e Tchambuli, esse medo de Mead era bastante factível.

Dobrin e Bashkow narram uma história que pode nos dar uma dimensão da preocupação de Mead. Suas cartas à Ruth Benedict demonstram como ela fez esforços enormes para evitar que Fortune fosse contratado por Boas para ser seu assistente na universidade de Columbia. Mead escreve literalmente que tê-lo por perto seria um grande problema, principalmente antes do lançamento do livro. Ela e Ruth chegaram ao ponto de organizar uma operação para afastar 
Fortune dos EUA: simularam um financiamento de algum milionário excêntrico para Columbia, indexado à produção de conhecimento sobre a Nova Guiné. O dinheiro veio da conta da própria Mead, pagando para o futuro ex-marido voltar ao campo e passar ao menos dois anos por lá, tempo em que ela poderia lançar Sexo e Temperamento sem problemas e sem a possibilidade da crítica de Fortune (Thomas, 2009:305). As duas antropólogas convenceram até mesmo Boas sobre o dinheiro "excêntrico", fazendo com que a proposta de trabalho de assistente que ele tinha em mãos para Fortune parecesse uma opção pior. Fortune nunca soube que o dinheiro vinha, efetivamente, de Mead e prestava contas de seu uso para Boas, quem imaginava ser o responsável por gerenciar os recursos.

"It will take everything I have saved, but I think it would be worth it. It would send Reo back to the southern hemisphere, with a chance of his staying there and getting placed... He will not of course be told where the money comes from, but will think we got it out of [a] millionaire"known to Benedict. "Of course, we don't want Papa Franz to know where [the initial donation] comes from" either. Mead "considered Africa instead, but it's more expensive."'Ruth and I have gone over it and over and it seems fool proof," she reported to Bateson." (Mead apud Dobrin e Bashkow, 2010:87)

Em outra carta para Bateson, Mead afirma:

"I have got to get this Sex and Temperament book published under the status quo and while Reo is off the scene of action or he might attack it disastrously. If it gets a six months start of his attack, then the attack won't matter." (Mead apud Dobrin e Bashkow, 2010:88)

Mais adiante, quando Reo Fortune voltou aos Arapesh, após ter frustrada a estadia em outros lugares da Nova Guiné, Mead fez de tudo para tirá-lo de lá, alegando que os fundos que cedera anonimamente a Fortune o impediam de estudar qualquer sociedade já conhecida.

Assim, a narrativa sobre Fortune deve muito aos temores de Mead, afirmam Dobrin e Bashkow. O romance de King, amparado naturalmente no ponto de vista de Mead sobre os eventos (a fonte principal de informações para o livro são aquelas produzidas por Mead ao longo de sua vida, bem como livros sobre a trajetória da autora), reforça a visão dela sobre Fortune. Ou seja, temos, evidentemente, um daqueles casos onde a verdade está com o vencedor. Prevalece até hoje a visão de 
Mead sobre Reo Fortune, para azar da memória do antropólogo neozelandês. Isso nos permite pensar como a escrita da história de nossa disciplina é completamente permeada por muito mais do que conjecturas sobre os trabalhos acadêmicos, sendo cruzada por lutas pessoais, desavenças amorosas, lutas por poder de toda ordem. E como, muito comumente, tomamos a palavra dos vencedores como fato.

O trabalho de Dobrin e Bashkow e alguns poucos outros indicam um outro Fortune (Thomas, 2009). Certamente alguém incomum, cuja produtividade após os anos iniciais caiu brutalmente, de quem se contam anedotas em Cambridge, onde ele manteve uma lectureship de 1947 a 1971 . Há, inclusive, indícios de uma personalidade explosiva, dada a ataques. Mas há, também, o relato de como ele se colocou contra o governo colonial da Nova Guiné em favor das populações com que dividiu o trabalho de campo, recusando-se a compartilhar o conhecimento produzido antropologicamente com os governantes, por medo de represálias aos "nativos".

Se parte da obra que escreveu após o período Sepik é realmente criptográfica e referente a uma crítica constante à teoria dos quadrados, há que se reconhecer a importância de obras como o Sorcerers of Dobu e, principalmente, do artigo "A Note on Some Forms of Kinship Structure" (Fortune, 1933), cujo teor antecipa questões fundamentais para o debate sobre parentesco no século XX. E mesmo sua crítica mais organizada ao trabalho de Mead, o seu artigo "Arapesh Warfare" (Fortune, 1939), pode ser visto como uma forma muito educada de exposição de suas dúvidas sobre a descrição que Mead apresenta desta sociedade. Fortune, que acompanhou o ponto de vista masculino dos Arapesh sobre o mundo, acreditava que a guerra e a violência organizada eram parte da estrutura de vida, contrariando algumas das afirmações de Mead sobre o ponto de vista essencialmente pacífico dos Arapesh. O romance de King, portanto, constrói um personagem a partir de Fortune que certamente não lhe faz jus.

\section{Considerações finais}

Essa longa reflexão sobre o romance Euphoria, de Lily King, tentou conjeturar sobre como uma ficção novelizada de um trecho da história da antropologia pode interessar a antropólogas/os em geral. ${ }^{16}$ Estruturei a resposta a esta questão em torno de três eixos principais: como o romance pode despertar o interesse na história da antropologia, como o romance explora a conexão entre vida e teoria, trazendo uma contribuição efetiva para o pensamento antropo- 
lógico e, por fim, como as narrativas que informam o romance impactam na imagem pública dos personagens e/ ou como estas mesmas narrativas estão inseridas no jogo de poder da constituição da história do pensamento antropológico.

A conexão livre entre esses três aspectos pode responder à pergunta inicial: o romance interessa ao público antropológico em várias dimensões. O livro nos faz pensar sobre a história do pensamento, sobre como determinadas versões predominam sobre outras, sobre como alguns personagens ganham destaque, sobre como a vida e a teoria estão intrincados a ponto de, em casos como o da "teoria dos quadrados", não ser possível dizer se a teoria atende aos anseios pessoais ou o se a teoria é feita para analisar a própria vida pessoal.

Em qualquer dessas dimensões, a leitura ganha ainda com o fato de que o livro é realmente fácil de se ler como romance, que a história prende o leitor do começo ao fim e que as angústias dos personagens são muito bem construídas, ao ponto de chegarmos as senti-las. Reflexão com prazer na leitura é coisa a se aproveitar nos dias de hoje.

Recebido: 07/02/2018

Aprovado: 01/03/2018

Igor José de Renó Machado é antropólogo com doutorado pela UNICAMP (2003) e pós-doutorado pelo Museu Nacional (2016). É professor Associado na Universidade Federal de São Carlos e Coordenador do Laboratório de Estudos Migratórios. Contato: igor@ufscar.br

\section{Notas}

1. O livro foi publicado em português em 2015 (King, 2015).

2. Para isso, o leitor pode se entreter com resenhas do The Guardian. Disponível em: <https://www.theguardian.com/books/2014/dec/24/euphoria-lily-king-review-margaret-mead-new-guinea>, do New York Times. Disponível em: <https:/ / www.nytimes.com/2014/06/08/books/review/euphoria-by-lily-king.html>; e 
doWashington Post. Disponível em: < https://www.washingtonpost.com/entertainment/books/euphoria-a-novel-based-on-margaret-mead-by-lily-king/2014/06/17/ e2a7bc36-f197-11e3-914c-1fbd0614e2d4_story.html?utm_term=.beb6d71258bb>. Acesso em: 05 jun. 2018, entre muitas outras.

3. Cf. entrevista da autora. Disponível em: <https://lareviewofbooks.org/article/ four-questions-lily-king/\#!> Acesso em: 06 fev. 2018.

4. Cf. disponível em: <http://www.triquarterly.org/interviews/lily-king-interview >. Acesso em: 06 fev. 2018.

5. O livro de Caffey e Francis (2006) faz uma coletânea dessas cartas, por exemplo.

6. "Novelização" aparece neste texto como um nome para o que Lily King produziu com o seu livro: uma história de ficção a partir de eventos narrados da vida de Margaret Mead,Reo Fortune e Gregory Bateson, sem compromisso com qualquer factualidade, mas relacionada com as várias narrativas produzidas a partir dos eventos.

7. "Quadrados" (squares) é o nome que Mead, Bateson, Fortune e Ruth Benedict usavam para se referir à teoria, segundo Dobrin e Bashkow (2010:81). Lily King usa a palavra "grade" (grid).

8. Pode-se acessar o esboço da teoria disponível em: <http:/ /www.loc.gov/exhibits/mead/images/mm0142p1s.jpg >. Acesso em: 25 fev. 2018.

9. Trechos de duas cartas de Fortune à Mead (uma de 1934 e outra de 1935, parte do acervo de Margaret Mead na Biblioteca do Congresso, EUA).

10. Vale destacar que temos acesso a diferentes narrativas sobre esses "fatos reais", permitindo-nos contrastá-las e, de forma alguma, defini-las.

11. Para um resumo, ver Côté (2000) e Shankman, P. (2009).

12. Ver entrevista com Paul Shankman. Disponível em:

<https: / / www.colorado.edu/asmagazine/2017/12/01/both-sides-misunderstand-margaret-mead-prof-contends $>$. Acesso em: 02 fev. 2018.

13. Cf. Disponível em: <https://thomashyllanderiksen.net/2015/05/17/sex-and-temperament-mead-bateson-and-fortune-new-guinea-1933/>. Acesso em: $02 \mathrm{fev}$. 2018.

14. Cf. Disponível em: <https://savageminds.org/2014/09/04/the-private-lives-of-anthropologists-a-review-of-lily-kings-euphoria/> . Acesso em: 02 fev. 2018.

15. Cf. Disponível em: <http://almagottlieb.com/category/reo-fortune/> Acesso em: 02 fev. 2018.

16. Para uma discussão em outros termos sobre a relação entre vidas e teorias em antropologia, ver Sigaud (1999). 


\section{Referências bibliográficas}

BATESON, Gregory. 2006. Naven: um esboço dos problemas sugeridos por um retrato compósito, realizado a partir de três perspectivas, da cultura de uma tribo da Nova Guiné. São Paulo: Editora da Universidade de São Paulo.

BATESON, Mary Catherine. 1984. With a Daughter's Eye:A Memoir of Margaret Mead and Gregory Bateson. New York: William Morrow.

BENEDICT, Ruth. 2013. Padrões de cultura. Petrópolis: Editora Vozes Limitada.

CAFFEY, Margaret M., and Patricia A. Francis, eds. 2006. To Cherish the Life of the World: Selected Letters of Margaret Mead. New York: Basic Books.

CÔTÉ, James E. 2000. The Mead-Freeman Controversy in Review.Journal ofYouth and Adolescence, v. 29, n. 5, p. 525-538.

DOBRIN, Lise M.; BASHKOW, Ira. 2010. "The Truth in Anthropology Does Not Travel First Class”: Reo Fortune's Fateful Encounter with Margaret Mead.Histories of Anthropology Annual, v. 6, n. 1, p. 66-128.

FORTUNE, Reo Franklin. Sorcerers of Dobu (Revised Edition). 1963. Londres: Routledge \& Kegan Paul.

FORTUNE, Reo. 1933. A Note on Some Forms of Kinship Structure. Oceania $4: 1-9$.

1939. Arapesh Warfare. American Anthropologist 41:22-41.

FREEMAN, D. 1983. Margaret Mead and Samoa: The Making and Unmaking of an Anthropological Myth. Cambridge: Harvard University Press.

HOWARD, Jane. 1984. Margaret Mead:A Life. New York: Simon and Schuster.

JUNG, Carl Gustav. 2011.Tipos psicológicos. Petrópolis: Editora Vozes Limitada.

KING, Lily. 2014. Euphoria. Nova York: Atlantic Monthly Press. . Euforia. 2015. São Paulo: Globo.

LAPSLEY, Hilary. 2001. Margaret Mead and Ruth Benedict: the kinship of women. Amherst: Univ of Massachusetts Press.

MALINOWSKI, Bronislaw. 1978. Argonautas do pacífico ocidental. São Paulo: Abril Cultural, v. 2.

MARGARET, M. E. A. D. 2000. Sexo e temperamento. São Paulo: Perspectiva.

MEAD, M. 1973 [1928]. Coming of Age in Samoa:A Psychological Study of PrimitiveYouth forWestern Civilization. New York: Morrow Quill Paperbacks.

MEAD, Margaret [and Reo Fortune]. "Summary Statement on the Problem of Personality and Culture." Tchambuli, 1933. Page 1. Additional handwritten notes by Reo Fortune, probably June-July 1935. Typescript photocopy. Manuscript Division, Library 
of Congress (142). Disponível em : <http://www.loc.gov/exhibits/mead/images/ mm0142p1s.jpg >. Acesso em: jan. de 2018. . 1972. BlackberryWinter, My earlier years. New York: Morow. 305 pp.

SHANKMAN, Paul. 2009. The trashing of Margaret Mead: anatomy of an anthropological controversy. Madison: Univ of Wisconsin Press.

SIGAUD, Lygia. 1999. As vicissitudes do "ensaio sobre o dom”. Mana, 5(2): 89-123.

THOMAS, Caroline. "Rediscovering Reo: Reflection on the Life and Professional Career of Reo Franklin Fortune”. In Gang of Four: Gregory Bateson, Ruth Benedict, Reo Fortune, and Margaret Mead in Multiple Contexts. Gerald Sullivan and Sharon Tiffany, eds. Special issue, Pacific Studies 32(2-3):299-324. 2009.

Resumo: Esse ensaio pretende discutir, de um ponto de vista acadêmico, as potencialidades de um texto ficcional sobre um momento da história da antropologia. Trata-se do livro "Euphoria", de Lily King, que cria uma ficção em torno do encontro de Margaret Mead, Reo Fortune e Gregory Bateson na Nova Guiné na passagem de 1931 para 1932.

Palavras-chave: Lily King, Margaret Mead, Reo Fortune, Gregory Bateson, história da antropologia, literatura.
Abstract: This essay intends to discuss, from an academic point of view, the potentialities of a fictional text about a moment in the history of anthropology. The book is "Euphoria" by Lily King, which creates a fiction around the meeting of Margaret Mead, Reo Fortune and Gregory Bateson in New Guinea in the passage from 1931 to 1932 .

Keywords: Lily King, Margaret Mead, Reo Fortune, Gregory Bateson, history of anthropology, literature. 